\title{
Parathyroid Gland Capsule
}

National Cancer Institute

\section{Source}

National Cancer Institute. Parathyroid Gland Capsule. NCI Thesaurus. Code C33265.

The thin fibrous lining that divides the parathyroid gland into lobules. 